\title{
Paraaortic Lymph Node Dissection in Endometrial Cancer; Is It Necessary?
}

\author{
Omer DIZDAR ${ }^{1}$, Arzu OGUZ ${ }^{1}$, Nadire KUCUKOZTAS ${ }^{1}$, Polat DURSUN ${ }^{2}$, Ozden ALTUNDAG ${ }^{1}$, Ali AYHAN ${ }^{2}$ \\ ${ }^{1}$ Baskent University, Department of Medical Oncology \\ ${ }^{2}$ Baskent University, Department of Obstetrics and Gynecology, Ankara, TURKEY
}

To the Editor;

Controversy persists on the benefit and extent of paraaortic lymph node dissection (PALND) in patients with endometrioid endometrial carcinoma (EC). Morbidity (lymphedema, cellulitis), cost and increased operation time are major disadvantages of PALND. ASTEC trial did not demonstrate survival benefit favoring lymphadenectomy. ${ }^{1}$ On the other hand, retrospective SEPAL study showed disease free survival and overall survival benefit with PALND in intermediate and high risk patients with uterine cancer. Risk assessment was based on disease stage, histological subtype, grade and lymph-vascular space invasion (LVSI) in this study. ${ }^{2}$ Recently Kumar et al showed 3 independent predictors of paraaortic metastases or recurrence (PAMR) in patients with endometrioid EC; Positive pelvic nodes, $>50 \%$ myometrial invasion and lymphovascular space invasion. Given the low reliability of pelvic lymph nodes and LVSI in intra-operative frozen section, they found that omitting PALND in all patients with $\leq 50 \%$ myometrial invasion would affect 84\% (792/946 patients) of the total cohort with a $1.1 \%$ risk of PAMR. ${ }^{3}$

We have assessed the utility of outer myometrial invasion as a criterion for omitting PALND in our patients with endometrioid EC diagnosed and operated between 2007 and $2012(n=330)$ at Baskent University Hospital, Ankara, Turkey. All patients had undergone comprehensive surgical staging including pelvic-paraaortic lymph node dissection. Median number of pelvic lymph nodes removed was 30 and para-aortic lymph nodes was 7. Median tumor size was $3 \mathrm{~cm}$ (range $0.1-18 \mathrm{~cm}$ ).
Histological grade was 1 in 176 patients (53\%), 2 in 118 patients (36\%) and 3 in 36 patients (11\%). Ten patients (3\%) had paraaortic lymph node metastases (PALNM). Among 218 patients with no or inner myometrial involvement, none had PALNM while 10 of 102 patients (8.9\%) with outer $1 / 2$ involvement had PALNM. Median follow up was 29 months. 13 patients had recurrence on follow up. Only two patients had paraaortic nodal recurrence, both had outer myometrial invasion on primary surgery pathology. One of the patients had isolated paraaortic nodal recurrence 20 months after first diagnosis and was treated with chemoradiation and currently disease-free 2 years post-radiotherapy. Second patient had multiple bone metastases and paraaortic nodal recurrence 8 months after the first diagnosis and died 15 months thereafter. Therefore, our data is consistent with the study of Kumar et al. In our series, 218/330 (66\%) of the patients could be spared from PALND based on the extent of myometrial involvement alone given that none of these patients had PALNM on surgical staging and none had paraaortic nodal recurrence on follow-up. In a comprehensively staged population of patients with endometrioid EC, we suggest that absence of outer MI can reliably identify patients in whom PALND can be omitted safely. Algorithms incorporating this and other parameters can help surgeons tailor the need for lymphadenectomy and identify a subgroup who can be treated with more conservative surgery. 
International Journal of Hematology and Oncology

\section{REFERENCES}

1. ASTEC study group, Kitchener H, Swart AM, Qian Q, et al. Efficacy of systematic pelvic lymphadenectomy in endometrial cancer (MRC ASTEC trial): a randomised study. Lancet 373: 125-136, 2009

2. Todo Y, Kato H, Kaneuchi M, et al. Survival effect of para-aortic lymphadenectomy in endometrial cancer (SEPAL study): a retrospective cohort analysis. Lancet 375: 1165-1172, 2010.

3. Kumar S, Mariani A, Bakkum-Gamez JN, et al. Risk factors that mitigate the role of paraaortic lymphadenectomy in uterine endometrioid cancer. Gynecol Oncol 130: 441-445, 2013.

\section{Correspondence}

Dr. Arzu OĞUZ

Bașkent Üniversitesi Hastanesi

Tıbbi Onkoloji Anabilim dalı

Mareşal Fevzi Çakmak Caddesi

53. sokak No:48

Bahçelievler, ANKARA / TURKEY

Tel: (+90.506) 4546990 / (+90.312) 2122912

Fax: (+90.312) 2152509

E-Mail: oguzarzu@yahoo.com 